\title{
Medical treatment of osteoporotic vertebral fractures
}

\author{
Bente Lomholt Langdahl and Torben Harsløf
}

\begin{abstract}
A vertebral fracture is a serious symptom of osteoporosis. Vertebral fractures cause moderate-to-severe back pain for a shorter or longer duration, increase the risk of a subsequent vertebral fracture approximately four-fold, reduce quality of life significantly and are associated with increased mortality. In order to choose the optimal treatment for the patient, the severity and type of osteoporosis should be investigated. Prevention of new osteoporotic fractures can be accomplished through treatment with both antiresorptive and anabolic treatments. The antiresorptive treatment modalities comprise calcium, vitamin $D$, bisphosphonates, hormone therapy, selective oestrogen receptor modulators (SERMs), strontium ranelate, receptor activator of NF- $\kappa B$ ligand (RANKL) antibody and calcitonin. The anabolic treatments comprise teriparatide and parathyroid hormone [(PTH)-(1-84)]. Adherence with treatment of osteoporosis is generally poor and therefore once the choice of treatment has been made and the patient has been instructed properly, long-term adherence to the treatment should be secured through information and regular control visits.
\end{abstract}

Keywords: adherence, bisphosphonate, oestrogen, osteoporosis, RANKL antibody, SERM, strontium ranelate, vertebral fracture

\section{Introduction}

Vertebral fractures are a serious problem in patients with osteoporosis. However, hip fractures have attracted much more interest because they are associated with increased morbidity and mortality and huge hospital and rehabilitation costs [Harvey et al. 2010]. Patients with vertebral fractures do not attract the same interest simply because vertebral fractures often are overlooked and therefore do not have a direct influence on healthcare cost. However, the prevalence of vertebral fractures increase the risk of a subsequent vertebral fracture approximately four-fold [Naves et al. 2003] and is associated with increased mortality [Ioannidis et al. 2009; Kado et al. 1999; Naves et al. 2003]. Vertebral fractures cause moderate-to-severe back pain for a shorter or longer duration. Hallberg and colleagues demonstrated that $48 \%$ of women suffering a vertebral fracture 7 years ago still used analgesics regularly and of these $44 \%$ were using opioids [Hallberg et al. 2009]. Furthermore, vertebral fractures reduce quality of life significantly [Oleksik et al. $2005,2000]$ and the recovery of quality of life after a new vertebral fracture is less than after a hip fracture [Strom et al. 2008]. Owing to the morbidity and mortality associated with vertebral fractures, the vast majorities of guidelines on the treatment of osteoporosis recommend that patients with existing vertebral fractures be treated [International Osteoporosis Foundation, 2010].

From a clinical perspective, patients with vertebral fractures are very diverse. There is no typical patient. Most patients with vertebral fractures are women, however, many men are also affected and often more severely than women when diagnosed. The majority of patients suffer from primary osteoporosis, but secondary osteoporosis due to immunological, gastrointestinal or endocrine disorders or treatment with drugs that induce osteoporosis, for example glucocorticoids or aromatase inhibitors [Stein and Shane, 2003], is also common.

There are several aims of medical treatment in patients with vertebral fractures. If the vertebral fractures are painful, pain relief should be attempted. The treatment of painful vertebral fractures includes analgesics, physiotherapy and exercise [Bennell et al. 2010; Madureira et al.
Ther Adv Musculoskel Dis (2011) 3(1) 17-29 DOI: $10.1177 /$ 1759720X10392105

(C) The Author(s), 2011. Reprints and permissions: http://www.sagepub.co.uk/ journalsPermissions.nav

Correspondence to: Bente Lomholt Langdahl, MD, PhD, DMSc Department of Endocrinology and Internal Medicine, Aarhus Sygehus THG, Aarhus University Hospital, DK8000 Aarhus C, Denmark bente.langdahla aarhus.rm.dk

Torben Harsløf, MD, PhD Department of Endocrinology and Internal Medicine, Aarhus Sygehus THG, Aarhus University Hospital, DK-8000 Aarhus C, Denmark 
2010; Liu-Ambrose et al. 2005; Papaioannou et al. 2003; Malmros et al. 1998], patient education and in some special cases perhaps vertebroplasty or kyphoplasty [Buchbinder et al. 2009; Kallmes et al. 2009; Grafe et al. 2005]. Likewise, treatment should attempt to restore quality of life [Langdahl et al. 2009]. Finally, medical treatment should prevent new vertebral and nonvertebral fractures.

This review is focused on medical treatments that prevent new fractures. These treatments can be divided into anabolic and antiresorptive therapies based on their mode of action. Anabolic therapies of osteoporosis primarily stimulate osteoblasts and bone formation, whereas antiresorptive therapies primarily inhibit osteoclasts and bone resorption. Fracture prevention using these therapies includes at least two important components. First, the therapies should have demonstrated fracture prevention efficacy in well-conducted clinical trials comprising the relevant patients. Second, the patients should remain adherent to the treatments in order to achieve the fracture prevention efficacy seen in the clinical trials. Although this seems obvious, nonadherence has been demonstrated to be a major issue in the pharmacological treatment of osteoporosis as well as other diseases such as hypercholesterolemia, diabetes mellitus type 2 and hypertension.

\section{Calcium and vitamin D}

Calcium and vitamin $\mathrm{D}$ have been provided in the majority of the clinical studies investigating the fracture prevention efficacy of antiresorptive and anabolic treatments of osteoporosis. Calcium and vitamin $\mathrm{D}$ themselves have an antiresorptive effect through suppression of serum levels of parathyroid hormone (PTH) and stimulation of the mineralization of the bone. Calcium and vitamin $\mathrm{D}$ have been demonstrated to have modest antifracture efficacy [DIPART Group, 2010; Bischoff-Ferrari et al. 2009a, 2009b] and are generally considered a basic element of the treatment of osteoporosis.

\section{Antiresorptive therapies}

Antiresorptive therapies comprise bisphosphonates, hormone therapy, selective oestrogen receptor modulators (SERMs), strontium ranelate, receptor activator of NF- $\kappa \mathrm{B}$ ligand (RANKL) antibody and calcitonin. The common feature of these drugs is inhibition of bone resorption, but the underlying mechanisms and pharmacodynamics of the drugs are very different (Figure 1).

\section{Bisphosphonates}

Bisphosphonates inhibit bone resorption by inhibiting the mevalonate pathway and thereby the production of isoprenoid lipids. Isoprenoid lipids are utilized for the post-translational modification of small GTP-binding proteins that are essential for osteoclast function and survival [Russell et al. 2008]. The inhibition of osteoclast activity and subsequent bone resorption has been demonstrated in human bone biopsies [Recker et al. 2010, 2008; Eriksen et al. 2002; Chavassieux et al. 1997], where histomorphometric analyses have revealed significant reductions in activation frequency.

Different bisphosphonates are available for the prevention and treatment of osteoporosis. They differ by their affinity for bone and by way of administration [Russell et al. 2008]. The orally administrated bisphosphonates should be taken daily, weekly or monthly, whereas the intravenously administrated bisphosphonates are given every 3 months or yearly. Some of the available bisphosphonates were initially examined and approved as daily treatment regiments, but through the so-called 'bridging' studies, the drugs have also been found to be efficient when administrated in higher oral dosages weekly (alendronate and risedronate) [Brown et al. 2002; Rizzoli et al. 2002] or monthly (ibandronate) [Reginster et al. 2006] or intravenously every 3 months (ibandronate) [Eisman et al. 2008]. The absorption of orally administered bisphosphonates is poor, less than a few percent. It is therefore very important that the patients take the drugs while fasting in the morning with nothing but plain water and do not eat breakfast for 30-60 minutes thereafter. Intravenously administered zoledronic acid reduces biochemical markers of bone turnover more rapidly and more strongly than orally administered alendronate [Saag et al. 2007a]. Whether this has any relevance for the fracture prevention of the two treatments is unknown.

It is unclear how much antifracture efficacy differs between the different bisphosphonates because there have been no head-to-head comparisons (Table 1). Alendronate has demonstrated efficacy against vertebral fractures in postmenopausal women (relative risk in treated versus placebo $(\mathrm{RR})=0.55(0.45-0.67))$, in men $(\mathrm{RR}=0.11, p=0.02)$ and in glucocorticoidinduced osteoporosis $(\mathrm{RR}=0.10, p=0.03)$ and against nonvertebral $(\mathrm{RR}=0.84 \quad(0.74-0.94))$ 


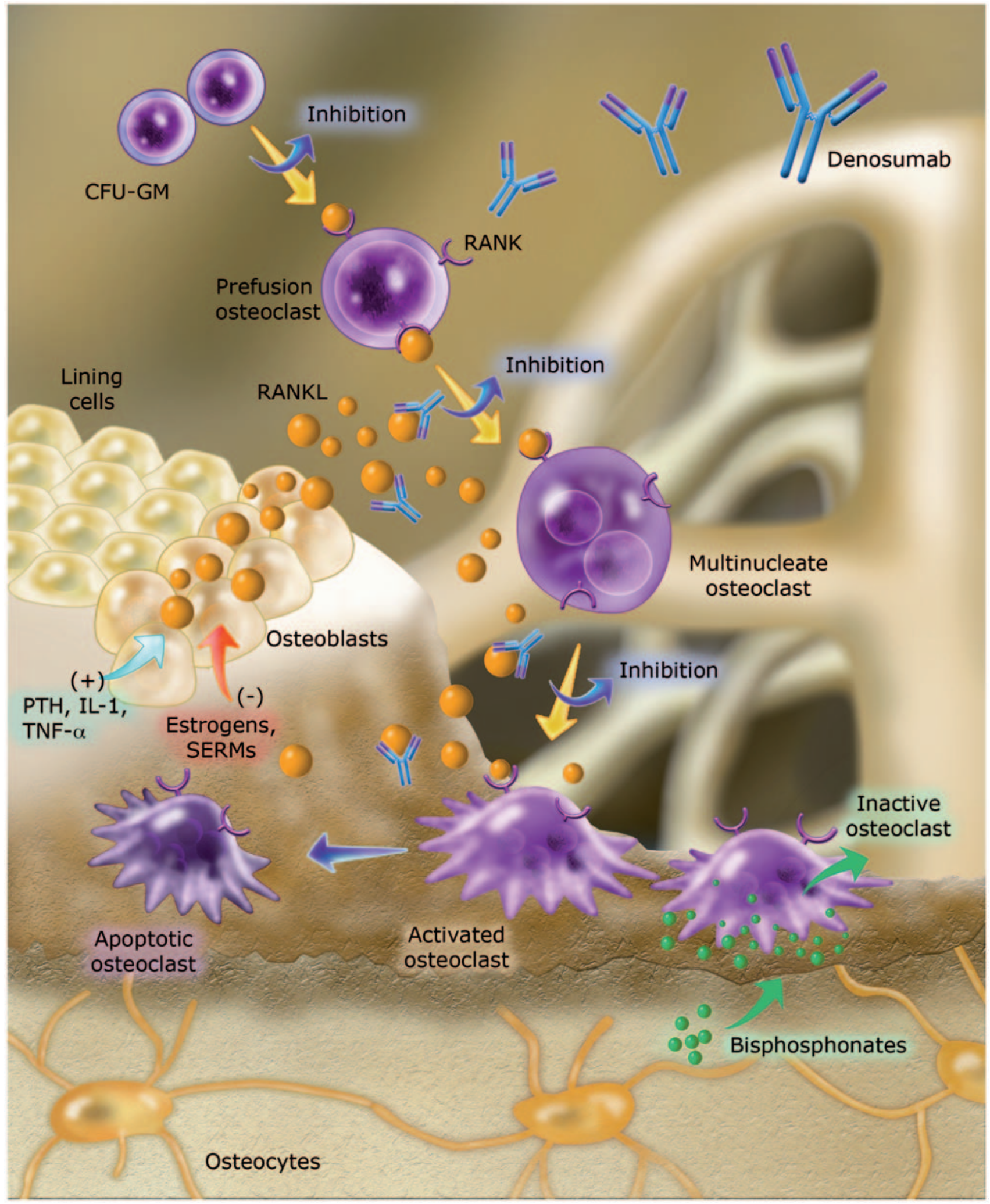

Figure 1. Illustration of the different mechanisms of actions of antiresorptive therapies. The yellow arrows indicate the normal recruitment and activation of osteoclasts. The red arrow indicates the effects of oestrogens and selective oestrogen receptor modulators (SERMs; inhibition of RANKL production by the osteoblasts). The light blue arrow indicates the effects of parathyroid hormone (PTH), interleukin 1 (IL-1) and tumour necrosis factor alpha (TNF- $\alpha$ ). The green arrows indicate the effects of bisphosphonates (inhibition of resorptive activity of the osteoclasts). The blue arrows indicate the effect of denosumab (inhibition of RANKL interaction with RANK). Illustration courtesy of Alessandro Baliani. 
Table 1. Antifracture efficacy of the most often used drugs for the primary and secondary prevention of osteoporotic fractures.

\begin{tabular}{|c|c|c|c|c|c|}
\hline \multirow[b]{2}{*}{ Drug } & \multicolumn{5}{|c|}{ Antifracture efficacy } \\
\hline & $\begin{array}{l}\text { Vertebral } \\
\text { fracture }\end{array}$ & Hip fracture & $\begin{array}{l}\text { Nonvertebral } \\
\text { fracture }\end{array}$ & $\begin{array}{l}\text { Glucocorticoid-induced } \\
\text { osteoporosis }\end{array}$ & $\begin{array}{l}\text { Male } \\
\text { osteoporosis }\end{array}$ \\
\hline $\begin{array}{l}\text { Antiresorptive } \\
\text { Alendronate } \\
\text { [Wells et al. 2008b; Adachi et al. 2001; } \\
\text { Orwoll et al. 2000; Black et al. 1996] }\end{array}$ & A & $A$ & $A$ & A & A \\
\hline $\begin{array}{l}\text { Risedronate } \\
\text { [Wells et al. 2008a; McClung et al. } \\
\text { 2001; Reginster et al. 2000; Reid } \\
\text { et al. 2000; Harris et al. 1999] }\end{array}$ & A & $A$ & $A$ & A & \\
\hline $\begin{array}{l}\text { Ibandronate } \\
\text { [Chesnut et al. 2004] }\end{array}$ & A & & $\mathrm{C}$ & & \\
\hline $\begin{array}{l}\text { Zoledronic acid } \\
\text { [Reid et al. 2009; Black et al. 2007; } \\
\quad \text { Lyles et al. 2007] }\end{array}$ & A & $A$ & $A$ & B & $A^{*}$ \\
\hline $\begin{array}{l}\text { Raloxifene } \\
\text { [Ettinger et al. 1999] }\end{array}$ & A & & & & \\
\hline $\begin{array}{l}\text { Strontium ranelate } \\
\text { [Reginster et al. 2005; Meunier et al. } \\
\text { 2004] }\end{array}$ & A & $\mathrm{C}$ & $A$ & & \\
\hline $\begin{array}{l}\text { Denosumab } \\
\text { [Cummings et al. 2009] }\end{array}$ & A & $A$ & A & & \\
\hline $\begin{array}{l}\text { Anabolic } \\
\text { Teriparatide } \\
\text { [Saag et al. 2007b; Neer et al. 2001] }\end{array}$ & A & & $A$ & A & \\
\hline PTH(1-84) [Greenspan et al. 2007] & A & & & & \\
\hline
\end{tabular}

and hip fractures $(\mathrm{RR}=0.61(0.40-0.92))$ [Wells et al. 2008b; Adachi et al. 2001; Orwoll et al. 2000; Black et al. 1996]. Risedronate has demonstrated efficacy against vertebral fractures in postmenopausal women $(\mathrm{RR}=0.63 \quad(0.51-0.77))$ and in glucocorticoid-induced osteoporosis $(\mathrm{RR}=0.30, p=0.04)$ and against nonvertebral $(R R=0.80 \quad(0.72-0.90))$ and hip fractures $(\mathrm{RR}=0.74 \quad(0.59-0.94))$ [Wells et al. 2008a; McClung et al. 2001; Reginster et al. 2000; Reid et al. 2000; Harris et al. 1999]. Ibandronate has demonstrated efficacy against vertebral fractures in postmenopausal women $(\mathrm{RR}=0.48$ (0.32-0.72)) [Chesnut et al. 2004]. Zoledronic acid has demonstrated efficacy against vertebral fractures in postmenopausal women $(\mathrm{RR}=0.30$ (0.24-0.38)), in men and women combined $(\mathrm{RR}=0.54(0.32-0.92))$ and in glucocorticoidinduced osteoporosis and against nonvertebral
$(\mathrm{RR}=0.75 \quad(0.64-0.87))$ and hip fractures $(\mathrm{RR}=0.59(0.42-0.89))$ [Reid et al. 2009; Black et al. 2007; Lyles et al. 2007].

Side effects to orally administrated bisphosphonates are primarily related to upper gastrointestinal discomfort, nausea and gastric ulcer. For both the orally and intravenously administrated aminobisphosphonates, flu-like symptoms can occur in relation to the first administrations. Other rare side effects are muscle and joint pain and uveitis. Very rarely seen side effects include osteonecrosis of the jaw (estimated prevalence between 1 in 10,000 and 1 in 100,000 patients) [Khosla et al. 2007] and atypical femoral fractures (prevalence 3 per 10,000 patient years) [Shane et al. 2010]. Bisphosphonates have been under investigation for increasing the risk of atrial fibrillation. However, it now seems unlikely that 
atrial fibrillation is related to the use of bisphosphonates. Further details on the side effects to treatment with bisphosphonates can be found in a recently published review [Abrahamsen, 2010]. Bisphosphonates are excreted by the kidneys and should not be administrated to patients with reduced kidney function (glomerular filtration rate $[\mathrm{GFR}]<30 \mathrm{ml} / \mathrm{min})$.

\section{Hormone therapy}

Hormone therapy in postmenopausal women has been used for decades for the prevention and treatment of osteoporosis. Recent clinical studies have demonstrated that hormone therapy prevents vertebral, nonvertebral and hip fractures. However, the same studies have also demonstrated that hormone therapy increases the risk of breast cancer and cardiovascular diseases [Jackson et al. 2006; Cauley et al. 2003]. Owing to these serious side effects, hormone therapy is not recommended for the prevention or treatment of osteoporosis by most health authorities.

\section{Selective oestrogen receptor modulators}

SERMs are drugs that bind to the two oestrogen receptors in a different way than oestrogen and thereby confer some effects similar to oestrogen, for example protection against bone loss and osteoporosis, some effects in contrast to oestrogen, for example protection against breast cancer, and appear to have no or only minor effects on other organs known to respond to oestrogen, for example the uterus.

Raloxifene is the only SERM approved by the authorities for the prevention and treatment of postmenopausal osteoporosis. The underlying mechanism of action is similar to that of oestrogen in postmenopausal women: inhibition of osteoclast recruitment and activity through reduced production of RANKL by the osteoblasts, leading to reduced bone resorption [Ott et al. 2002]. Raloxifene is administered orally as a daily tablet. It has demonstrated efficacy against vertebral fractures $(R R=0.70$ $(0.50-0.80))$ in postmenopausal women (Table 1) [Ettinger et al. 1999] and reduces the risk of breast cancer by more than 60\% [Martino et al. 2004]. Side effects include hot flushes, restless legs, peripheral oedema, gallstones, rarely venous thromboembolism and very rarely fatal outcome of stroke in women with ischemic heart disease [Mosca et al. 2009]. Raloxifene is metabolized in the liver and is not recommended in patients with severely impaired renal and hepatic functions.

Two other SERMs, lasofoxifene and bazedoxifene, have recently been investigated in large clinical trials and have proved antifracture efficacy, but are as-yet not approved by the authorities [Cummings et al. 2010; Silverman et al. 2008].

\section{Strontium ranelate}

Strontium ranelate has demonstrated efficacy against vertebral fractures $(R R=0.63$ $(\mathrm{CI}=0.56-0.71))$ and nonvertebral fractures $(\mathrm{RR}=0.86 \quad(\mathrm{CI}=0.75-0.98)) \quad$ in postmenopausal women (Table 1) [O'Donnell et al. 2006; Reginster et al. 2005; Meunier et al. 2004]. The underlying mechanism of action is not completely understood. Strontium can replace calcium in bone and suppress bone resorption, perhaps through the calcium-sensing receptor. It has also been suggested that strontium ranelate increases the ratio of OPG/RANKL and thereby inhibit osteoclast recruitment and activity [Arlot et al. 2008]. Strontium ranelate is administered orally as a powder dissolved in plain water every day. Side effects are nausea, loose stools, venous thromboembolism, dermatitis, headache and impaired memory and very rarely allergic reactions including the DRESS syndrome. Strontium is excreted by the kidneys and should therefore not be administrated to patients with severely reduced renal function (GFR $<30 \mathrm{ml} / \mathrm{min}$ ).

\section{RANKL antibody}

Denosumab is a fully human antibody against RANKL. It is administered as a subcutaneous injection every 6 months. The mechanism of action is inhibition of the interaction between RANKL and RANK, the receptor for RANKL on preosteoclasts and mature osteoclasts. This results in inhibition of osteoclast activity [Reid et al. 2010]. The effect of denosumab is very rapid and a pronounced reduction in osteoclast activity is seen already within the first 24 hours after administration [Saag et al. 2007a]. Denosumab has demonstrated efficacy against vertebral $(\mathrm{RR}=0.32(0.26-0.41))$, nonvertebral $(\mathrm{RR}=0.80 \quad(0.67-0.95))$ and hip fractures $(\mathrm{RR}=0.60 \quad(0.37-0.97))$ in postmenopausal women (Table 1) [Cummings et al. 2009]. Side effects include skin rashes, skin, respiratory and urinary tract infections, cataract and very rarely osteonecrosis of the jaw. 


\section{Calcitonin}

Calcitonin is administered as a nasal spray for osteoporosis. It has been reported to prevent vertebral fractures $(R R=0.46(0.25-0.87))$ in postmenopausal women, but not nonvertebral fractures. However, the number of women lost to follow up in the clinical trials was generally high and the results should therefore be interpreted with caution [Chesnut et al. 2000].

\section{Treatment duration}

Osteoporosis is a chronic disease and in this perspective it may seem counterintuitive to discuss duration of treatment as the treatment of other chronic diseases such as hypertension, hypercholesterolemia, type 2 diabetes, etc. is life-long. However, because bisphosphonates attach strongly to bone and therefore are retained in the bone for many years depending on the affinity of the individual bisphosphonate, a limited duration of treatment is potentially possible in some patients. The best examined bisphosphonate with respect to treatment duration is alendronate. The FLEX study that was a follow-up study to the FIT study, has demonstrated that it is safe to treat for 10 years with alendronate based on the fact that bone biopsies showed intact remodelling activity [Schwartz et al. 2010; Black et al. 2006]. The study also demonstrated that in postmenopausal women without vertebral fractures and nonosteoporotic hip bone mineral density $(\mathrm{BMD}$; i.e. T-score $>-2.5)$ after 5 years treatment, it may be possible to stop alendronate treatment and still be protected against new fractures. However, women with existing vertebral fractures and osteoporotic hip BMD (T-score below -2.5), on the other hand, probably need to continue the treatment in order to stay protected against fractures [Schwartz et al. 2010; Black et al. 2006]. These results make it possible for the clinician and the patient to make an individualized decision regarding the duration of treatment.

Similar information is not available for the other bisphosphonates and a similar conclusion therefore cannot be made with certainty. The other antiresorptive treatments do not have prolonged duration of the effect and therefore only have antifracture efficacy as long as the patient remains adherent to the therapy.

\section{Bone anabolic therapies}

Bone anabolic therapies have been sought for many years, and fluoride and growth hormone have been investigated but found not to be clinically useful. PTH has also been investigated for its anabolic effects on bone. However, only after it became possible to produce recombinant PTH or analogues thereof has the development of PTH for clinical use in the treatment of osteoporosis become possible. The underlying mechanism of action is not completely understood yet. However, studies have demonstrated that the duration of elevated levels of PTH in the circulation is critical for the actions of PTH. Short-term elevation predominately stimulates osteoblasts, whereas continuously elevated levels stimulate both osteoclasts and osteoblasts, resulting in a high bone turnover condition similar to primary hyperparathyroidism characterized by bone loss.

The PTH analogue teriparatide comprises the first 34 amino acids of the intact PTH. A daily subcutaneous injection with teriparatide rapidly stimulates bone formation [Jiang et al. 2003] leading to a substantial increase in bone mass and reduction in fractures. Teriparatide has demonstrated efficacy against vertebral $(R R=0.35$ $(0.22-0.55))$ and nonvertebral fractures $(\mathrm{RR}=0.47(0.25-0.88)) \quad$ in postmenopausal women and in glucocorticoid-induced osteoporosis [Saag et al. 2007b; Neer et al. 2001]. The treatment is now approved for 24 months in both Europe and the United States. In Europe $\mathrm{PTH}(1-84)$ is also approved for the treatment of osteoporosis. $\mathrm{PTH}(1-84)$ has demonstrated efficacy against vertebral fractures $(R R=0.60$ $(0.36-1.00))$ in postmenopausal women (Table 1) [Greenspan et al. 2007]. Side effects include nausea, fatigue, perspiration, palpitations, hypercalcaemia, depression, urinary incontinence and bone pain.

The effect of treatment with PTH on BMD is rapidly lost when the treatment is stopped. This can be prevented by treatment with antiresorptive therapy, but not with supplementation with calcium and vitamin D alone [Eastell et al. 2009]. It is therefore very important that patients treated with PTH are followed closely and prescribed an antiresorptive drug when treatment with PTH treatment is completed.

The increase in BMD during bone anabolic treatment is blunted in patients that have been treated with antiresorptive therapies prior to the bone anabolic treatment. The stronger the antiresorptive therapy, the more pronounced the blunting of the effect. However, a recent study seems to 
show that the blunting can be at least partly overcome by extending the duration of treatment with teriparatide from 18 to 24 months [ObermayerPietsch et al. 2008]. Whether blunting of the effect on BMD or overcoming it by treating for a longer time is relevant for the antifracture efficacy of the drug is unknown. That the duration of treatment may be important for at least the nonvertebral antifracture efficacy of teriparatide has been suggested by a recent publication by Lindsay and colleagues demonstrating a positive correlation between duration of treatment and antifracture efficacy [Lindsay et al. 2009].

The combination of antiresorptive and anabolic treatments have also been investigated, but without convincing evidence for an additive effect. However, recently a small study investigating the combination of teriparatide and zoledronic acid demonstrated a positive effect of the combination at hip sites compared with teriparatide alone and a similar effect at the lumbar spine suggesting that this combination can be considered in patients where anabolic treatment would be desirable, but the potential loss of bone at the hip site needs further study [Cosman et al. 2010].

\section{Adherence}

Potent antiresorptive and anabolic treatments are available for the treatment of postmenopausal osteoporosis. There is also good evidence for efficacy of at least some of the treatments in male osteoporosis and in glucocorticoid-induced osteoporosis (Table 1). However, another equally important factor for successful prevention of osteoporotic fractures is adherence to the therapy. Adherence is the combination of persistence and compliance. Unfortunately, many studies have demonstrated insufficient adherence with different osteoporosis therapies [Cooper et al. 2006; Cramer et al. 2005; Recker et al. 2005] and that the outcome of the treatment is attenuated by poor adherence. Eastell and colleagues demonstrated a reduced reduction in biochemical markers of bone resorption in women nonadherent to therapy with risedronate [Eastell et al. 2003]. Sebaldt and colleagues demonstrated an impaired increase in BMD in women nonadherent to therapy with bisphosphonates [Sebaldt et al. 2004]. Other studies have demonstrated significant impaired reduction in fracture rate in women nonadherent to osteoporosis therapies [Siris et al. 2006; Caro et al. 2004]. A very important way of improving fracture prevention in the future is therefore to improve adherence to treatment. Many factors are important for adherence [Tosteson et al. 2003]. The disease and the patient's perception of the disease are important. Adherence to treatment of a symptomatic disease is higher than that of a nonsymptomatic disease. The patient's perception of the treatment with respect to efficacy is important. Also factors related to administration of the treatment are important: dosing frequencies, dosing procedures and formulation of the drug. Side effects are also important and a common cause of nonadherence. Patients should therefore be informed about the existence of other treatment options if they experience side effects with the chosen treatment. The cost and the possibilities for reimbursement are also factors that should be considered when choosing a treatment for the individual patient. Finally, it is important to remember that most patients with osteoporosis are unlike the patients in the clinical trials. In the clinic many patients have several comorbidities that may have an influence on the treatment of osteoporosis in different ways. The comorbidities can be more symptomatic than osteoporosis and therefore receive more attention from the patient, comorbidities can make it more difficult for the patient to tolerate treatment for osteoporosis, and for example patients with dyspepsia tolerate bisphosphonates less well and concomitant treatment with glucocorticoids increases the risk of peptic ulcers. Comorbidities can also make it more difficult for the patient to administer osteoporosis treatments correctly. For example patients with mild forms of dementia can have difficulties remembering to take weekly bisphosphonates and to wait for $30 \mathrm{~min}-$ utes before eating breakfast.

In order to improve adherence, all patients should be considered as patients with potentially poor adherence. This knowledge should therefore be included when planning the treatment of the individual patient.

\section{Clinical practice}

The first obstacle to the treatment of patients with osteoporotic vertebral fractures is the identification of these patients. Patients with back pain (that could be caused by vertebral fractures) are often not examined with this possibility in mind. X-rays of the spine or chest are often taken for other reasons than osteoporosis and even though vertebral fractures are visible, the fractures are often not mentioned in the radiology report [Gehlbach et al. 2000]. Even when 
mentioned in the radiology report, the clinicians often do not pay attention to this important information. Clinicians and radiologists need to work together to improve the diagnosis of patients with vertebral fractures. A relatively new tool that may help diagnosing patients with vertebral fractures is the 'vertebral fracture assessment' modality on dual-energy X-ray absorptiometry (DXA) machines. With this tool it has become possible to reliably detect at least moderate or severe vertebral fractures at a reduced cost and with minimum exposure of patients to radiation [McCloskey et al. 2008; Chapurlat et al. 2006].

Once a patient has been diagnosed with one or more vertebral fractures, the patient needs to undergo further examinations to clarify the type and severity of the disease. The number and severity of the vertebral fractures should be evaluated by X-ray. The severity of a vertebral fracture can be described as mild, moderate or severe using either semiquantitative methods [Genant et al. 1993; McCloskey et al. 1993] or be described as a percentage reduction of vertebral body height using quantitative methods. In many countries some of the drugs registered for the treatment of patients with vertebral fractures are only reimbursed if the patient has a certain number of fractures with a specific severity. Information about nonvertebral, low-energy trauma fractures is also relevant as not all treatments are equally efficient in preventing this type of fracture. If the patient in addition to vertebral fractures has also suffered, for example, a hip fracture, a drug that prevents both types of fractures should be considered.

The severity of osteoporosis can be further investigated by measuring BMD by DXA and bone turnover by biochemical markers of bone resorption and formation. Broadly speaking, if BMD is profoundly low, a bone anabolic drug would be preferred and if bone turnover is very high a drug that reduces bone turnover quickly would be preferable. Finally, the investigation of the patients should include information about whether the disease is secondary to other diseases or medical treatments and if these are modifiable. For example, if a patient is being treated with glucocorticoids, reduction in the dose should be considered and a drug that has proven efficacy against glucocorticoid-induced osteoporosis should be preferred. Biochemical work-up can unravel secondary causes of osteoporosis, for example vitamin $\mathrm{D}$ deficiency or subclinical hyperthyroidism, as well as contraindications for some of the treatments, for example renal insufficiency.

Once the type and severity of osteoporosis have been worked out, the physician and the patient should discuss treatment options. In most patients weekly alendronate will be the first drug of choice because alendronate has welldocumented antifracture efficacy and safety and is cheap. However, in some patients other treatments should be considered. If osteoporosis is severe with very low BMD or multiple vertebral fractures, bone anabolic treatment with PTH should be considered. If the patient has previously suffered nonvertebral fractures or a hip fracture, treatments with documented antifracture efficacy against these types of fractures should be preferred; again, weekly alendronate would be the first choice. If the patient is treated with glucocorticoids, treatments with documented antifracture efficacy in glucocorticoidinduced osteoporosis should be preferred. If the patient is a man, treatments with documented antifracture efficacy in men should be preferred. On top of these considerations, comorbidity and lifestyle of the patient should be taken into account. If the patient has recent history of peptic ulcer, reflux or difficulties swallowing, oral bisphosphonates should be avoided. If the patient has a history of venous thromboembolism, hormone treatment, SERMs and strontium ranelate should be avoided. If the patient needs to take medication before being able to get out of bed, for example pain killers, absorption of oral bisphosphonates may be affected. If the patient has dementia or trouble remembering the day of the week, oral bisphosponates will be a problem unless a family member or a home nurse can help. If the evenings include enjoying tea, coffee and cakes or other foods, strontium ranelate is not the optimal choice because the patient needs to be fasting for 2 hours before taking the drug at bedtime.

Once a choice of treatment has been made and the patient has been properly instructed, longterm adherence to the treatment should be attended to. This could involve education of the patient with respect to the disease and the treatment [Silverman et al. 1997]. This could also be achieved through membership of an active patient organization. A follow-up visit at the clinic within the first 3 months after starting treatment with or without measuring biochemical 
markers of bone turnover has been demonstrated to improve adherence [Clowes et al. 2004]. It is also important to inform the patient that there are other treatments available and that if the patient experiences symptoms believed to be side effects, the patient should contact the clinic either to be reassured that the symptoms are not side effects or to find another suitable treatment.

\section{Conclusion}

Both anabolic and antiresorptive treatments with proven antifracture efficacy and acceptable safety and tolerability are available for the prevention of the next fracture in patients with prevalent vertebral fractures. However, vertebral fractures are still often overlooked and therefore the patients are far too often not offered this treatment. The patient with one or more vertebral fractures needs a thorough examination in order to characterize the type and severity of osteoporosis. On basis of this and information about comorbidities and the patient's preferences, the right treatment for the individual patient should be chosen. Once treatment has been initiated an effort should be made to ensure adherence with the treatment.

\section{Funding}

This research received no specific grant from any funding agency in the public, commercial, or notfor-profit sectors.

\section{Conflict of interest statement}

Bente Langdahl has received honoraria for consulting from Amgen, Eli Lilly, Novartis and Nycomed and received research support from Amgen, Eli Lilly, Merck, Sharp \& Dohme, Novartis, Nycomed and Pfizer. Torben Harsløf has received research support from Novartis.

\section{References}

Abrahamsen, B. (2010) Adverse effects of bisphosphonates. Calcif Tissue Int 86: 421-435.

Adachi, J.D., Saag, K.G., Delmas, P.D., Liberman, U.A., Emkey, R.D., Seeman, E. et al. (2001) Two-year effects of alendronate on bone mineral density and vertebral fracture in patients receiving glucocorticoids: a randomized, double-blind, placebo-controlled extension trial. Arthritis Rheum 44: 202-211.

Arlot, M.E., Jiang, Y., Genant, H.K., Zhao, J., Burt-Pichat, B., Roux, J.P. et al. (2008)

Histomorphometric and microCT analysis of bone biopsies from postmenopausal osteoporotic women treated with strontium ranelate. $\mathcal{F}$ Bone Miner Res 23: $215-222$.

Bennell, K.L., Matthews, B., Greig, A., Briggs, A., Kelly, A., Sherburn, M. et al. (2010) Effects of an exercise and manual therapy program on physical impairments, function and quality-of-life in people with osteoporotic vertebral fracture: a randomised, single-blind controlled pilot trial. BMC Musculoskelet Disord 11: 36

Bischoff-Ferrari, H.A., Dawson-Hughes, B., Staehelin, H.B., Orav, J.E., Stuck, A.E., Theiler, R. et al. (2009a) Fall prevention with supplemental and active forms of vitamin D: a meta-analysis of randomised controlled trials. BMF 339: b3692.

Bischoff-Ferrari, H.A., Willett, W.C., Wong, J.B., Stuck, A.E., Staehelin, H.B., Orav, E.J. et al. (2009b) Prevention of nonvertebral fractures with oral vitamin $\mathrm{D}$ and dose dependency: a meta-analysis of randomized controlled trials. Arch Intern Med 169: 551-561.

Black, D.M., Cummings, S.R., Karpf, D.B., Cauley, J.A., Thompson, D.E., Nevitt, M.C. et al. (1996)

Randomised trial of effect of alendronate on risk of fracture in women with existing vertebral fractures. Fracture Intervention Trial Research Group [see comments]. Lancet 348: 1535-1541.

Black, D.M., Delmas, P.D., Eastell, R., Reid, I.R., Boonen, S., Cauley, J.A. et al. (2007) Once-yearly zoledronic acid for treatment of postmenopausal osteoporosis. N Engl f Med 356: 1809-1822.

Black, D.M., Schwartz, A.V., Ensrud, K.E., Cauley, J.A., Levis, S., Quandt, S.A. et al. (2006) Effects of continuing or stopping alendronate after 5 years of treatment: the Fracture Intervention Trial Long-term Extension (FLEX): a randomized trial. $\mathcal{F} A M A$ 296: 2927-2938.

Brown, J.P., Kendler, D.L., McCLung, M.R., Emkey, R.D., Adachi, J.D., Bolognese, M.A. et al. (2002) The efficacy and tolerability of risedronate once a week for the treatment of postmenopausal osteoporosis. Calcif Tissue Int 71: 103-111.

Buchbinder, R., Osborne, R.H., Ebeling, P.R., Wark, J.D., Mitchell, P., Wriedt, C. et al. (2009) A randomized trial of vertebroplasty for painful osteoporotic vertebral fractures. $N$ Engl f Med 361: 557-568.

Caro, J.J., Ishak, K.J., Huybrechts, K.F., Raggio, G. and Naujoks, C. (2004) The impact of compliance with osteoporosis therapy on fracture rates in actual practice. Osteoporos Int 15: 1003-1008.

Cauley, J.A., Robbins, J., Chen, Z., Cummings, S.R., Jackson, R.D., LaCroix, A.Z. et al. (2003) Effects of estrogen plus progestin on risk of fracture and bone mineral density: the Women's Health Initiative randomized trial. fAMA 290: 1729-1738.

Chapurlat, R.D., Duboeuf, F., Marion-Audibert, H.O., Kalpakcioglu, B., Mitlak, B.H. and Delmas, P.D. (2006) Effectiveness of instant vertebral assessment to detect prevalent vertebral fracture. Osteoporos Int 17: 1189-1195. 
Chavassieux, P.M., Arlot, M.E., Reda, C., Wei, L., Yates, A.J. and Meunier, P.J. (1997) Histomorphometric assessment of the long-term effects of alendronate on bone quality and remodeling in patients with osteoporosis. F Clin Invest 100: 1475-1480.

Chesnut III, C.H., Silverman, S., Andriano, K., Genant, H., Gimona, A., Harris, S. et al. (2000) A randomized trial of nasal spray salmon calcitonin in postmenopausal women with established osteoporosis: the prevent recurrence of osteoporotic fractures study. PROOF Study Group. Am F Med 109: 267-276.

Chesnut III, C.H., Skag, A., Christiansen, C., Recker, R., Stakkestad, J.A., Hoiseth, A. et al. (2004) Effects of oral ibandronate administered daily or intermittently on fracture risk in postmenopausal osteoporosis. f Bone Miner Res 19: 1241-1249.

Clowes, J.A., Peel, N.F. and Eastell, R. (2004) The impact of monitoring on adherence and persistence with antiresorptive treatment for postmenopausal osteoporosis: a randomized controlled trial. $f$ Clin Endocrinol Metab 89: 1117-1123.

Cooper, A., Drake, J. and Brankin, E. (2006) Treatment persistence with once-monthly ibandronate and patient support vs. once-weekly alendronate: results from the PERSIST study. Int $\mathcal{F}$ Clin Pract 60: 896-905.

Cosman, F., Eriksen, E.F., Recknor, C., Miller, P.D., Guanabens, N., Kasperk, C. et al. (2010) Effects of intravenous zoledronic acid plus subcutaneous teriparatide $[(1-34) \mathrm{rhPTH}]$ in postmenopausal osteoporosis. $\mathcal{F}$ Bone Miner Res, in press.

Cramer, J.A., Amonkar, M.M., Hebborn, A. and Altman, R. (2005) Compliance and persistence with bisphosphonate dosing regimens among women with postmenopausal osteoporosis. Curr Med Res Opin 21: 1453-1460.

Cummings, S.R., Ensrud, K., Delmas, P.D., LaCroix, A.Z., Vukicevic, S., Reid, D.M. et al. (2010) Lasofoxifene in postmenopausal women with osteoporosis. N Engl f Med 362: 686-696.

Cummings, S.R., San Martin, J., McCLung, M.R., Siris, E.S., Eastell, R., Reid, I.R. et al. (2009) Denosumab for prevention of fractures in postmenopausal women with osteoporosis. $N \mathrm{Engl} \mathcal{F} \mathrm{Med}$ 361: 756-765.

DIPART (Vitamin D Individual Patient Analysis of Randomized Trials) Group (2010) Patient level pooled analysis of 68500 patients from seven major vitamin D fracture trials in US and Europe. BMF 340: b5463.

Eastell, R., Garnero, P. and Vrijens, B. (2003) Influence of patient compliance with risedronate therapy on bone turnover marker and bone density response: the IMPACT study. Calcif Tissue Int 72: 297.

Eastell, R., Nickelsen, T., Marin, F., Barker, C., Hadji, P., Farrerons, J. et al. (2009) Sequential treatment of severe postmenopausal osteoporosis after teriparatide: final results of the randomized, controlled European
Study of Forsteo (EUROFORS). $\mathcal{F}$ Bone Miner Res 24: 726-736.

Eisman, J.A., Civitelli, R., Adami, S., Czerwinski, E., Recknor, C., Prince, R. et al. (2008) Efficacy and tolerability of intravenous ibandronate injections in postmenopausal osteoporosis: 2-year results from the DIVA Study. F Rheumatol 35: 488-497.

Eriksen, E.F., Melsen, F., Sod, E., Barton, I. and Chines, A. (2002) Effects of long-term risedronate on bone quality and bone turnover in women with postmenopausal osteoporosis. Bone 31: 620-625.

Ettinger, B., Black, D.M., Mitlak, B.H., Knickerbocker, R.K., Nickelsen, T., Genant, H.K. et al. (1999) Reduction of vertebral fracture risk in postmenopausal women with osteoporosis treated with raloxifene: results from a 3-year randomized clinical trial. Multiple Outcomes of Raloxifene Evaluation (MORE) Investigators. FAMA 282: 637-645.

Gehlbach, S.H., Bigelow, C., Heimisdottir, M., May, S., Walker, M. and Kirkwood, J.R. (2000) Recognition of vertebral fracture in a clinical setting. Osteoporos Int 11: 577-582.

Genant, H.K., Wu, C.Y., Van Kuijk, C. and Nevitt, M.C. (1993) Vertebral fracture assessment using a semiquantitative technique. $\mathcal{F}$ Bone Miner Res 8: 1137-1148.

Grafe, I.A., Da Fonseca, K., Hillmeier, J., Meeder, P.J., Libicher, M., Noldge, G. et al. (2005) Reduction of pain and fracture incidence after kyphoplasty: 1-year outcomes of a prospective controlled trial of patients with primary osteoporosis. Osteoporos Int 16: 2005-2012.

Greenspan, S.L., Bone, H.G., Ettinger, M.P., Hanley, D.A., Lindsay, R., Zanchetta, J.R. et al. (2007) Effect of recombinant human parathyroid hormone (1-84) on vertebral fracture and bone mineral density in postmenopausal women with osteoporosis: a randomized trial. Ann Intern Med 146: 326-339.

Hallberg, I., Bachrach-Lindstrom, M., Hammerby, S., Toss, G. and Ek, A.C. (2009) Health-related quality of life after vertebral or hip fracture: a seven-year followup study. BMC Musculoskelet Disord 10: 135.

Harris, S.T., Watts, N.B., Genant, H.K., McKeever, C.D., Hangartner, T., Keller, M. et al. (1999) Effects of risedronate treatment on vertebral and nonvertebral fractures in women with postmenopausal osteoporosis: a randomized controlled trial. Vertebral Efficacy With Risedronate Therapy (VERT) Study Group. $\mathcal{F} A M A$ 282: 1344-1352.

Harvey, N., Dennison, E. and Cooper, C. (2010) Osteoporosis: impact on health and economics. Nat Rev Rheumatol 6: 99-105.

International Osteoporosis Foundation (2010) IOF list of national-regional guidelines. http:// www.iofbonehealth.org.

Ioannidis, G., Papaioannou, A., Hopman, W.M., Akhtar-Danesh, N., Anastassiades, T., Pickard, L. 
et al. (2009) Relation between fractures and mortality: results from the Canadian Multicentre Osteoporosis Study. CMAF 181: 265-271.

Jackson, R.D., Wactawski-Wende, J., LaCroix, A.Z., Pettinger, M., Yood, R.A., Watts, N.B. et al. (2006) Effects of conjugated equine estrogen on risk of fractures and BMD in postmenopausal women with hysterectomy: results from the women's health initiative randomized trial. F Bone Miner Res 21: $817-828$.

Jiang, Y., Zhao, J.J., Mitlak, B.H., Wang, O., Genant, H.K. and Eriksen, E.F. (2003) Recombinant human parathyroid hormone (1-34) [teriparatide] improves both cortical and cancellous bone structure. $\mathcal{F}$ Bone Miner Res 18: 1932-1941.

Kado, D.M., Browner, W.S., Palermo, L., Nevitt, M.C., Genant, H.K. and Cummings, S.R. (1999) Vertebral fractures and mortality in older women: a prospective study. Study of Osteoporotic Fractures Research Group. Arch Intern Med 159: 1215-1220.

Kallmes, D.F., Comstock, B.A., Heagerty, P.J., Turner, J.A., Wilson, D.J., Diamond, T.H. et al. (2009) A randomized trial of vertebroplasty for osteoporotic spinal fractures. N Engl F Med 361: 569-579.

Khosla, S., Burr, D., Cauley, J., Dempster, D.W., Ebeling, P.R., Felsenberg, D. et al. (2007)

Bisphosphonate-associated osteonecrosis of the jaw: report of a task force of the American Society for Bone and Mineral Research. F Bone Miner Res 22: 1479-1491.

Langdahl, B.L., Rajzbaum, G., Jakob, F., Karras, D., Ljunggren, O., Lems, W.F. et al. (2009) Reduction in fracture rate and back pain and increased quality of life in postmenopausal women treated with teriparatide: 18-month data from the European Forsteo Observational Study (EFOS). Calcif Tissue Int 85: 484-493.

Lindsay, R., Miller, P., Pohl, G., Glass, E.V., Chen, P. and Krege, J.H. (2009) Relationship between duration of teriparatide therapy and clinical outcomes in postmenopausal women with osteoporosis. Osteoporos Int 20: 943-948.

Liu-Ambrose, T.Y., Khan, K.M., Eng, J.J., Lord, S.R., Lentle, B. and McKay, H.A. (2005) Both resistance and agility training reduce back pain and improve health-related quality of life in older women with low bone mass. Osteoporos Int 16: 1321-1329.

Lyles, K.W., Colon-Emeric, C.S., Magaziner, J.S., Adachi, J.D., Pieper, C.F., Mautalen, C. et al. (2007) Zoledronic acid and clinical fractures and mortality after hip fracture. N Engl f Med 357: 1799-1809.

Madureira, M.M., Bonfa, E., Takayama, L. and Pereira, R.M. (2010) A 12-month randomized controlled trial of balance training in elderly women with osteoporosis: improvement of quality of life. Maturitas 66: 206-211.

Malmros, B., Mortensen, L., Jensen, M.B. and Charles, P. (1998) Positive effects of physiotherapy on chronic pain and performance in osteoporosis. Osteoporos Int 8: 215-221.

Martino, S., Cauley, J.A., Barrett-Connor, E., Powles, T.J., Mershon, J., Disch, D. et al. (2004) Continuing outcomes relevant to Evista: breast cancer incidence in postmenopausal osteoporotic women in a randomized trial of raloxifene. $\mathcal{F}$ Natl Cancer Inst 96: 1751-1761.

McCloskey, E.V., Spector, T.D., Eyres, K.S., Fern, E.D., O'Rourke, N., Vasikaran, S. et al. (1993) The assessment of vertebral deformity: a method for use in population studies and clinical trials. Osteoporos Int 3: $138-147$.

McCloskey, E.V., Vasireddy, S., Threlkeld, J., Eastaugh, J., Parry, A., Bonnet, N. et al. (2008) Vertebral fracture assessment (VFA) with a densitometer predicts future fractures in elderly women unselected for osteoporosis. F Bone Miner Res 23: 1561-1568.

McClung, M.R., Geusens, P., Miller, P.D., Zippel, H., Bensen, W.G., Roux, C. et al. (2001) Effect of risedronate on the risk of hip fracture in elderly women. Hip Intervention Program Study Group. $N$ Engl f Med 344: 333-340.

Meunier, P.J., Roux, C., Seeman, E., Ortolani, S., Badurski, J.E., Spector, T.D. et al. (2004) The effects of strontium ranelate on the risk of vertebral fracture in women with postmenopausal osteoporosis. $N$ Engl $\mathcal{F}$ Med 350: 459-468.

Mosca, L., Grady, D., Barrett-Connor, E., Collins, P., Wenger, N., Abramson, B.L. et al. (2009) Effect of raloxifene on stroke and venous thromboembolism according to subgroups in postmenopausal women at increased risk of coronary heart disease. Stroke 40: $147-155$.

Naves, M., Diaz-Lopez, J.B., Gomez, C., RodriguezRebollar, A., Rodriguez-Garcia, M. and CannataAndia, J.B. (2003) The effect of vertebral fracture as a risk factor for osteoporotic fracture and mortality in a Spanish population. Osteoporos Int 14: 520-524.

Neer, R.M., Arnaud, C.D., Zanchetta, J.R., Prince, R., Gaich, G.A., Reginster, J.Y. et al. (2001) Effect of parathyroid hormone (1-34) on fractures and bone mineral density in postmenopausal women with osteoporosis. N Engl f Med 344: 1434-1441.

O’Donnell, S., Cranney, A., Wells, G.A., Adachi, J.D. and Reginster, J.Y. (2006) Strontium ranelate for preventing and treating postmenopausal osteoporosis. Cochrane Database Syst Rev, CD005326.

Obermayer-Pietsch, B.M., Marin, F., McCloskey, E.V., Hadji, P., Farrerons, J., Boonen, S. et al. (2008) Effects of two years of daily teriparatide treatment on BMD in postmenopausal women with severe osteoporosis with and without prior antiresorptive treatment. F Bone Miner Res 23: 1591-1600.

Oleksik, A., Lips, P., Dawson, A., Minshall, M.E., Shen, W., Cooper, C. et al. (2000) Health-related quality of life in postmenopausal women with low 
BMD with or without prevalent vertebral fractures. f Bone Miner Res 15: 1384-1392.

Oleksik, A.M., Ewing, S., Shen, W., van Schoor, N.M. and Lips, P. (2005) Impact of incident vertebral fractures on health related quality of life (HRQOL) in postmenopausal women with prevalent vertebral fractures. Osteoporos Int 16: 861-870.

Orwoll, E., Ettinger, M., Weiss, S., Miller, P., Kendler, D., Graham, J. et al. (2000) Alendronate for the treatment of osteoporosis in men. $N$ Engl f Med 343: 604-610.

Ott, S.M., Oleksik, A., Lu, Y., Harper, K. and Lips, P. (2002) Bone histomorphometric and biochemical marker results of a 2-year placebo-controlled trial of raloxifene in postmenopausal women. $\mathcal{F}$ Bone Miner Res 17: $341-348$.

Papaioannou, A., Adachi, J.D., Winegard, K., Ferko, N., Parkinson, W., Cook, R.J. et al. (2003) Efficacy of home-based exercise for improving quality of life among elderly women with symptomatic osteoporosisrelated vertebral fractures. Osteoporos Int 14: 677-682.

Recker, R.R., Delmas, P.D., Halse, J., Reid, I.R., Boonen, S., Garcia-Hernandez, P.A. et al. (2008) Effects of intravenous zoledronic acid once yearly on bone remodeling and bone structure. $\mathcal{F}$ Bone Miner Res 23: 6-16.

Recker, R.R., Gallagher, R. and MacCosbe, P.E. (2005) Effect of dosing frequency on bisphosphonate medication adherence in a large longitudinal cohort of women. Mayo Clin Proc 80: 856-861.

Recker, R.R., Ste-Marie, L.G., Langdahl, B., Czerwinski, E., Bonvoisin, B., Masanauskaite, D. et al. (2010) Effects of intermittent intravenous ibandronate injections on bone quality and micro-architecture in women with postmenopausal osteoporosis: the DIVA study. Bone 46: 660-665.

Reginster, J., Minne, H.W., Sorensen, O.H., Hooper, M., Roux, C., Brandi, M.L. et al. (2000) Randomized trial of the effects of risedronate on vertebral fractures in women with established postmenopausal osteoporosis. Vertebral Efficacy with Risedronate Therapy (VERT) Study Group. Osteoporos Int 11: 83-91.

Reginster, J.Y., Adami, S., Lakatos, P., Greenwald, M., Stepan, J.J., Silverman, S.L. et al. (2006) Efficacy and tolerability of once-monthly oral ibandronate in postmenopausal osteoporosis: 2 year results from the MOBILE study. Ann Rheum Dis 65: 654-661.

Reginster, J.Y., Seeman, E., De Vernejoul, M.C., Adami, S., Compston, J., Phenekos, C. et al. (2005) Strontium ranelate reduces the risk of nonvertebral fractures in postmenopausal women with osteoporosis: Treatment of Peripheral Osteoporosis (TROPOS) study. F Clin Endocrinol Metab 90: 2816-2822.

Reid, D.M., Devogelaer, J.P., Saag, K., Roux, C., Lau, C.S., Reginster, J.Y. et al. (2009) Zoledronic acid and risedronate in the prevention and treatment of glucocorticoid-induced osteoporosis (HORIZON): a multicentre, double-blind, double-dummy, randomised controlled trial. Lancet 373: 1253-1263.

Reid, D.M., Hughes, R.A., Laan, R.F., Sacco-Gibson, N.A., Wenderoth, D.H., Adami, S. et al. (2000) Efficacy and safety of daily risedronate in the treatment of corticosteroid-induced osteoporosis in men and women: a randomized trial. European CorticosteroidInduced Osteoporosis Treatment Study. $\mathcal{F}$ Bone Miner Res 15: 1006-1013.

Reid, I.R., Miller, P.D., Brown, J.P., Kendler, D.L., Fahrleitner-Pammer, A., Valter, I. et al. (2010) Effects of denosumab on bone histomorphometry: the FREEDOM and STAND studies. F Bone Miner Res 25: 2256-2265.

Rizzoli, R., Greenspan, S.L., Bone III, G., Schnitzer, T.J., Watts, N.B., Adami, S. et al. (2002) Two-year results of once-weekly administration of alendronate $70 \mathrm{mg}$ for the treatment of postmenopausal osteoporosis. F Bone Miner Res 17: 1988-1996.

Russell, R.G., Watts, N.B., Ebetino, F.H. and Rogers, M.J. (2008) Mechanisms of action of bisphosphonates: similarities and differences and their potential influence on clinical efficacy. Osteoporos Int 19: 733-759.

Saag, K., Lindsay, R., Kriegman, A., Beamer, E. and Zhou, W. (2007a) A single zoledronic acid infusion reduces bone resorption markers more rapidly than weekly oral alendronate in postmenopausal women with low bone mineral density. Bone 40: 1238-1243.

Saag, K.G., Shane, E., Boonen, S., Marin, F., Donley, D.W., Taylor, K.A. et al. (2007b) Teriparatide or alendronate in glucocorticoid-induced osteoporosis. N Engl F Med 357: 2028-2039.

Schwartz, A.V., Bauer, D.C., Cummings, S.R., Cauley, J.A., Ensrud, K.E., Palermo, L. et al. (2010) Efficacy of continued Alendronate for fractures in women with and without prevalent vertebral fracture: The FLEX trial. F Bone Miner Res 25: 976-982.

Sebaldt, R.J., Shane, L.G., Pham, B.Z., Cook, R.J., Thabane, L., Petrie, A. et al. (2004) Impact of noncompliance and non-persistence with daily bisphosphonates on longer-term effectiveness outcomes in patients with osteoporosis. F Bone Min Res 19: M423.

Shane, E., Burr, D., Ebeling, P.R., Abrahamsen, B., Adler, R.A., Brown, T.D. et al. (2010) Atypical subtrochanteric and diaphyseal femoral fractures: Report of a task force of the American Society for Bone and Mineral Research. $\mathcal{F}$ Bone Miner Res 25: 2267-2294.

Silverman, S.L., Christiansen, C., Genant, H.K., Vukicevic, S., Zanchetta, J.R., de Villiers, T.J. et al. (2008) Efficacy of bazedoxifene in reducing new vertebral fracture risk in postmenopausal women with osteoporosis: results from a 3-year, randomized, placebo-, and active-controlled clinical trial. F Bone Miner Res 23: 1923-1934.

Silverman, S.L., Greenwald, M., Klein, R.A. and Drinkwater, B.L. (1997) Effect of bone density information on decisions about hormone replacement 
therapy: a randomized trial. Obstet Gynecol 89: 321-325.

Siris, E.S., Harris, S.T., Rosen, C.J., Barr, C.E., Arvesen, J.N., Abbott, T.A. et al. (2006) Adherence to bisphosphonate therapy and fracture rates in osteoporotic women: relationship to vertebral and nonvertebral fractures from 2 US claims databases. Mayo Clin Proc 81: 1013-1022.

Stein, E. and Shane, E. (2003) Secondary osteoporosis. Endocrinol Metab Clin North Am 32: 115-134.

Strom, O., Borgstrom, F., Zethraeus, N., Johnell, O., Lidgren, L., Ponzer, S. et al. (2008) Long-term cost and effect on quality of life of osteoporosis-related fractures in Sweden. Acta Orthop 79: 269-280.
Tosteson, A.N., Grove, M.R., Hammond, C.S., Moncur, M.M., Ray, G.T., Hebert, G.M. et al. (2003) Early discontinuation of treatment for osteoporosis. Am F Med 115: 209-216.

Wells, G., Cranney, A., Peterson, J., Boucher, M., Shea, B., Robinson, V. et al. (2008a) Risedronate for the primary and secondary prevention of osteoporotic fractures in postmenopausal women. Cochrane Database Syst Rev CD004523.

Wells, G.A., Cranney, A., Peterson, J., Boucher, M., Shea, B., Robinson, V. et al. (2008b) Alendronate for the primary and secondary prevention of osteoporotic fractures in postmenopausal women. Cochrane Database Syst Rev CD001155.
Visit SAGE journals online http://tab.sagepub.com

(SAGEJOURNALS 